\title{
The association between transfer coefficient of the lung and the risk of exacerbation in asthma-COPD overlap: an observational cohort study
}

Hiroaki Ogata*, Katsuyuki Katahira, Aimi Enokizu-Ogawa, Yujiro Jingushi, Akiko Ishimatsu, Kazuhito Taguchi, Hiroko Nogami, Hiroshi Aso, Atsushi Moriwaki and Makoto Yoshida

\begin{abstract}
Background: Asthma-chronic obstructive pulmonary disease (COPD) overlap (ACO) patients experience exacerbations more frequently than those with asthma or COPD alone. Since low diffusing capacity of the lung for carbon monoxide $\left(D_{L C O}\right)$ is known as a strong risk factor for severe exacerbation in COPD, $D_{L C O}$ or a transfer coefficient of the lung for carbon monoxide $\left(\mathrm{K}_{\mathrm{CO}}\right)$ is speculated to also be associated with the risk of exacerbations in ACO.

Methods: This study was conducted as an observational cohort survey at the National Hospital Organization Fukuoka National Hospital. $\mathrm{D}_{L \mathrm{CO}}$ and $\mathrm{K}_{\mathrm{CO}}$ were measured in 94 patients aged $\geq 40$ years with a confirmed diagnosis of ACO. Multivariable-adjusted hazard ratios (HRs) for the exacerbation-free rate over one year were estimated and compared across the levels of $\mathrm{D}_{\mathrm{LCO}}$ and $\mathrm{K}_{\mathrm{CO}}$.

Results: Within one year, 33.3\% of the cohort experienced exacerbations. After adjustment for potential confounders, low $\mathrm{K}_{\mathrm{CO}}(<80 \%$ per predicted) was positively associated with the incidence of exacerbation (multivariable-adjusted $H R=3.71$ (95\% confidence interval 1.32-10.4)). The association between low $D_{L C O}(<80 \%$ per predicted) and exacerbations showed similar trends, although it failed to reach statistical significance (multivariable-adjusted HR $=1.31$ (95\% confidence interval 0.55-3.11)).

Conclusions: Low $K_{\text {CO }}$ was a significant risk factor for exacerbations among patients with ACO. Clinicians should be aware that ACO patients with impaired $\mathrm{K}_{\mathrm{CO}}$ are at increased risk of exacerbations and that careful management in such a population is mandatory.
\end{abstract}

Keywords: Asthma-COPD overlap, Diffusing capacity of the lung, Transfer coefficient of the lung, Exacerbation, Forced expiratory volume in $1 \mathrm{~s}$

*Correspondence: md105020@gmail.com

Department of Respiratory Medicine, National Hospital Organization

Fukuoka National Hospital, 4-39-1 Yakatabaru, Minami-ku,

Fukuoka 811-1394, Japan

\section{Background}

Over the last decade, the clinical characteristics of patients with coexisting asthma and chronic obstructive pulmonary disease (COPD), namely asthma-COPD overlap (ACO), have been matters of great concern for physicians $[1,2]$. A meta-analysis of epidemiological studies revealed that more than a quarter of COPD subjects were compatible with ACO [3]. Since the diffusing 
capacity and transfer coefficient of the lung for carbon monoxide $\left(\mathrm{D}_{\mathrm{LCO}}\right.$ and $\mathrm{K}_{\mathrm{CO}}$, respectively) are generally preserved in asthma and deficient in COPD $[2,4]$, they might vary widely among ACO cases depending on the proportion of each component of asthma or COPD. However, among patients with ACO, the distributions of $\mathrm{D}_{\mathrm{LCO}}$ and $\mathrm{K}_{\mathrm{CO}}$, as well as impairing factors for them, have not been investigated.

There is broad agreement that patients with ACO experience exacerbations more frequently than those with asthma or COPD alone [1,3]. With regard to COPD, exacerbations are an ideal target for risk-stratified treatment to lead to a higher health-related quality of life, longer life, and lower healthcare cost [5]. Recent evidence indicates that impairment in $\mathrm{D}_{\mathrm{LCO}}$ is a strong biomarker for predicting the risk of severe exacerbation in COPD [6]. It is assumed that $\mathrm{D}_{\mathrm{LCO}}$ or $\mathrm{K}_{\mathrm{CO}}$ can be applied as a risk factor for exacerbations in ACO; however, there has been no study evaluating this issue. Thus, assessing the influence of $\mathrm{D}_{\mathrm{LCO}}$ and $\mathrm{K}_{\mathrm{CO}}$ on $\mathrm{ACO}$ exacerbations could be of great benefit for improving health management for such patients.

Based on these considerations, the present study was conducted to evaluate the distributions of gas diffusion and transfer of the lung, explore factors that influence them, and assess their clinical usefulness in predicting future exacerbations among $\mathrm{ACO}$ patients.

\section{Methods}

\section{Study population}

The present study was conducted as an observational cohort study through a review of medical records at National Hospital Organization Fukuoka National Hospital. The cohort consisted of 94 ACO patients aged $\geq 40$ years who had an assessment of $\mathrm{D}_{\mathrm{LCO}}$ and $\mathrm{K}_{\mathrm{CO}}$ from June 1, 2017, to May 31, 2020, with complete information on all relevant covariates. ACO was defined as the presence of three major criteria: (i) persistent airflow limitation, that is, post-bronchodilator forced expiratory volume in $1 \mathrm{~s}$ to forced vital capacity (post-BD $\mathrm{FEV}_{1} /$ $\mathrm{FVC})<70 \%$; (ii) at least one feature associated with COPD; and (iii) one or more asthmatic features.

The COPD-like features were composed of (a) a smoking history of $>10$ pack-years and (b) pulmonary emphysema. The asthmatic features were as follows: (a) high values of fractional exhaled nitric oxide (FeNO) $(>35$ parts per billion (ppb)), (b) bronchodilator reversibility ( $\geq 12 \%$ and $\geq 200 \mathrm{ml}$ reversibility in post-BD FEV ${ }_{1}$ ), (c) an eosinophilic component (blood eosinophil levels $>300$ / $\mu \mathrm{l}$ and/or $>5 \%$ ), and (d) positive levels for total immunoglobulin E (IgE) (>170 IU/ml) and/or IgE specific to perennial inhalant antigens (>class 2 ). Subjects with $\geq 3$ asthmatic features were defined as "highly asthmatic" ones. The distribution of and affecting factors for $\mathrm{D}_{\mathrm{LCO}}$ per predicted ( $\mathrm{D}_{\mathrm{LCO}} \%$ pred) as well as $\mathrm{K}_{\mathrm{CO}}$ per predicted ( $\mathrm{K}_{\mathrm{CO}} \%$ pred) were evaluated as a cross-sectional analysis using the total cohort. After excluding 4 patients with no follow-up data, the remaining 90 patients were also recruited in the prospective research (the prospective cohort) in order to investigate the association of $\mathrm{D}_{\mathrm{LCO}} \%$ pred and $\mathrm{K}_{\mathrm{CO}} \%$ pred with exacerbations of $\mathrm{ACO}$.

\section{Assessment of diffusing capacity and transfer coefficient of the lung}

$\mathrm{D}_{\mathrm{LCO}}$ and $\mathrm{K}_{\mathrm{CO}}$ were measured via the single-breath method using CHESTAC-8900 (Chest Inc., Tokyo, Japan) in accordance with the American Thoracic Society / European Respiratory Society (ATS/ERS) guidelines [7]. $\mathrm{D}_{\mathrm{LCO}} \%$ pred was calculated using the predicted $\mathrm{D}_{\mathrm{LCO}}$ value for a person of the same age, gender, and body surface area [8]. Likewise, $\mathrm{K}_{\mathrm{CO}} \%$ pred was estimated based on the age-dependent prediction equation for $\mathrm{K}_{\mathrm{CO}}$ [8]. In accordance with the clinical review article [4], low $\mathrm{D}_{\mathrm{LCO}}$ and low $\mathrm{K}_{\mathrm{CO}}$ were defined as $\mathrm{D}_{\mathrm{LCO}} \%$ pred $<80 \%$ and $\mathrm{K}_{\mathrm{CO}}$ $\%$ pred $<80 \%$, respectively. When dividing the prospective cohort into three groups based on the tertile distribution of $\mathrm{D}_{\mathrm{LCO}} \%$ pred or $\mathrm{K}_{\mathrm{CO}} \%$ pred, the cut-off values were as follows: lowest, $\leq 82.0 \%$; middle, $82.1-108.72 \%$; and highest, $\geq 108.73 \%$ for $\mathrm{D}_{\mathrm{LCO}} \%$ pred; lowest, $\leq 79.9 \%$; middle, $80.0-97.9 \%$; and highest, $\geq 98.0 \%$ for $\mathrm{K}_{\mathrm{CO}} \%$ pred. To assess the robustness of the outcomes, we also estimated $\mathrm{D}_{\mathrm{LCO}} \%$ pred and $\mathrm{K}_{\mathrm{CO}} \%$ pred using another reference formula, namely the lambda, mu, and sigma method employed by the ERS Global Lung Function Initiative (GLI) Task Force [9].

\section{Clinical evaluations}

For each case, respiratory physicians reviewed the patient's medical records and assessed the demographic and clinical characteristics: age, gender, height, weight, smoking exposure, medical history, blood laboratory findings, spirometry, FeNO, computed tomography (CT) scans of the chest, and medical treatment for ACO, including systemic corticosteroid and inhaled long-acting bronchodilators (LABDs), namely long-acting $\beta_{2}$ agonists and long-acting muscarinic antagonists, and inhaled corticosteroid (ICSs). CT scanning was executed with a minimal slice thickness of $1-5 \mathrm{~mm}$. The proportion of subjects with systemic corticosteroid use was $8.5 \%$ among the entire cohort. Body mass index (BMI; $\mathrm{kg} / \mathrm{m}^{2}$ ) was calculated as weight divided by squared height. Overweight and underweight were defined as BMI $\geq 25.0 \mathrm{~kg} /$ $\mathrm{m}^{2}$ and $\mathrm{BMI}<18.5 \mathrm{~kg} / \mathrm{m}^{2}$, respectively. Spirometry was performed fifteen minutes after bronchodilator administration, in line with the guidelines of the Japanese Respiratory Society [10], using a CHESTAC-8900 spirometer 
(Chest MI, Tokyo, Japan). According to the Global Initiative for Chronic Obstructive Lung Disease (GOLD) criteria [11], the severity of ACO was defined using the predicted $\mathrm{FEV}_{1}$ value for a person of the same age, gender, and height using the equation for the Japanese population [12] as follows: mild, $\mathrm{FEV}_{1} \geq 80 \%$ of predicted; moderate, $50 \% \leq \mathrm{FEV}_{1}<80 \%$ of predicted; severe and very severe, $\mathrm{FEV}_{1}<50 \%$ of predicted. Based on the official statement of ATS/ERS [13], an exacerbation of ACO was defined as worsening symptoms that require treatment with oral/systemic corticosteroids and/or antibiotics for at least three days. Together with a radiologist, respiratory physicians interpreted the chest CT images for each case and scrutinised them for the presence of emphysema.

\section{Statistical analysis}

SAS University Edition software version 9.4 (SAS Institute, Cary, NC, USA) was used to perform all statistical analyses. A two-sided $P<0.05$ was considered to indicate statistical significance. The effects of the potential risk factors on the prevalence of low $\mathrm{D}_{\mathrm{LCO}}$ and low $\mathrm{K}_{\mathrm{CO}}$ were estimated as odds ratios (ORs) with $95 \%$ confidence intervals (95\% CIs) in a multivariable-adjusted logistic regression model, wherein adjustment was made for age, gender, BMI, $\mathrm{FEV}_{1}$, use of LABDs and ICSs, features associated with COPD (a smoking history of $>10$ pack-years, and emphysema), and those associated with asthma (high FeNO, bronchial reversibility, an eosinophilic component, and a positive total IgE and/or IgE specific to perennial inhalant antigens). Kaplan-Meier curves were constructed to show the exacerbation-free rate over the one-year period. Log-rank testing was performed to study the influence of low $\mathrm{D}_{\mathrm{LCO}}$ and low $\mathrm{K}_{\mathrm{CO}}$ on the cumulative incidence of exacerbations. The hazard ratios (HRs) with their 95\% CIs according to the levels of $\mathrm{D}_{\mathrm{LCO}} \%$ pred or $\mathrm{K}_{\mathrm{CO}} \%$ pred for the development of exacerbation were estimated using a Cox proportional hazards model adjusted for history of exacerbations in the previous year in addition to all aforementioned potential confounders. The same model was used to assess the linear trends in the risk of exacerbation across the tertile classification of $\mathrm{D}_{\mathrm{LCO}} \%$ pred or $\mathrm{K}_{\mathrm{CO}} \%$ pred.

Sensitivity analyses were performed using the patients without systemic corticosteroid use. Another analysis was conducted with GLI-based $\mathrm{D}_{\mathrm{LCO}} \%$ pred and $\mathrm{K}_{\mathrm{CO}} \%$ pred.

\section{Ethical considerations}

The study was approved by the National Hospital Organization Fukuoka National Hospital Institutional Review Board for Clinical Research (\#F3-3).

\section{Results}

\section{Distributions of DLCO \% pred and KCO \% pred}

Table 1 lists the demographic and clinical characteristics among the total cohort. The majority of the individuals were male $(81.9 \%)$, with smoking exposure of $\geq 10$ packyears $(92.6 \%)$ and with increased levels of total IgE and/ or IgE specific to perennial inhalant antigens (79.8\%). Nearly half of the total cohort (42.6\%) experienced exacerbations in the previous year. The distribution of severity was as follows: mild, $28.7 \%$; moderate, $42.6 \%$; and severe/ very severe, $28.7 \%$. The prevalence of highly asthmatic cases was higher among ICS users than among nonusers, although not statistically different $(37.5 \%$ vs. $20.0 \%$, respectively; $P=0.09$ ).

As in Fig. $1 \mathrm{~A}, \mathrm{~B}$, both $\mathrm{D}_{\mathrm{LCO}} \%$ pred and $\mathrm{K}_{\mathrm{CO}} \%$ pred showed approximately normal distributions. The prevalence of low $\mathrm{D}_{\mathrm{LCO}}$ among the subjects was $30.9 \%$. Decreases in $\mathrm{K}_{\mathrm{CO}}$ were also observed in about one-third of the subjects (34.0\%).

\section{Factors affecting DLCO \% pred and $\mathrm{KCO} \%$ pred}

$\mathrm{FEV}_{1}$ and the use of ICSs were inversely associated with low $\mathrm{D}_{\mathrm{LCO}}$ (multivariable-adjusted $\mathrm{OR}=0.29(95 \% \mathrm{CI}$ $0.10-0.76)$ for a 1-L increase in $\mathrm{FEV}_{1}$ and 0.07 (95\% CI 0.01-0.59) for ICS use, respectively) (Table 2), whereas neither of them independently affected the prevalence of low $\mathrm{K}_{\mathrm{CO}}$. On the other hand, LABD use was associated with neither low $\mathrm{D}_{\mathrm{LCO}}$ nor low $\mathrm{K}_{\mathrm{CO}}$. There was a negative relationship between $\mathrm{BMI}$ and low $\mathrm{K}_{\mathrm{CO}}$ (multivariable-adjusted $\mathrm{OR}=0.73$ (95\% CI $0.57-0.90)$ ). The prevalence of low $\mathrm{K}_{\mathrm{CO}}$ was significantly higher in subjects with emphysema than in those without (multivariableadjusted OR $=7.37$ (95\% CI 1.81-40.3)) (Table 3). While the prevalence of low $\mathrm{D}_{\mathrm{LCO}}$ was not statistically different between subjects with/without emphysema (multivariable-adjusted OR=1.32 (95\% CI 0.39-4.77)) (Table 2). Regarding other variables, there was no significant relationship to either low $\mathrm{D}_{\mathrm{LCO}}$ or low $\mathrm{K}_{\mathrm{CO}}$.

\section{Association of DLCO \% pred and KCO \% pred with exacerbations of ACO}

In the prospective cohort, 30 individuals $(33.3 \%$ of the cohort) experienced at least one event of ACO exacerbation within one year. The incidence rate of ACO exacerbations over one year was significantly higher in the low- $\mathrm{K}_{\mathrm{CO}}$ group than in the other $(P=0.002)$, while there was no significant difference between the low- and preserved$\mathrm{D}_{\mathrm{LCO}}$ groups $(P=0.11)$ (Fig. 2). The results were substantially similar after adjustment for potential confounders: there was a significant increase in $\mathrm{HR}$ in the low- $\mathrm{K}_{\mathrm{CO}}$ group as compared to the preserved- $\mathrm{K}_{\mathrm{CO}}$ group $(\mathrm{HR}=3.71$ (95\% CI 1.32-10.4)), whereas there was not for the $\mathrm{D}_{\mathrm{LCO}}$ 
Table 1 Mean values or frequencies of demographic and clinical characteristics

\begin{tabular}{|c|c|}
\hline Variables & $\begin{array}{l}\text { Mean values (standard deviation), median } \\
\text { values (interquartile range), or frequencies }\end{array}$ \\
\hline Male gender (\%) & 81.9 \\
\hline Age (years) & $69.8(9.1)$ \\
\hline Body surface area $\left(\mathrm{m}^{2}\right)$ & $1.66(0.19)$ \\
\hline Body mass index $\left(\mathrm{kg} / \mathrm{m}^{2}\right)$ & $22.7(3.4)$ \\
\hline Smoking history (pack-year) & $39.0(20.0-50.0)$ \\
\hline Smoking history $\geq 10$ pack-years (\%) & 92.6 \\
\hline Emphysema (\%) & 68.1 \\
\hline Blood eosinophil levels (\%) & $5.2(2.8-8.9)$ \\
\hline Blood eosinophil counts $(/ \mu l)$ & $351(150-538)$ \\
\hline Eosinophilic component (\%) & 59.6 \\
\hline FeNO (ppb) & $31.5(19.0-59.0)$ \\
\hline High FeNO (\%) & 46.8 \\
\hline Total lgE levels (IU/ml) & $406(119-868)$ \\
\hline Positive levels for total lgE and/or lgE specific to perennial inhalant antigens (\%) & 79.8 \\
\hline Bronchial reversibility (\%) & 19.1 \\
\hline $\mathrm{FEV}_{1}(\mathrm{I})$ & $1.64(0.67)$ \\
\hline \multicolumn{2}{|l|}{$\mathrm{FEV}_{1}$ per predicted } \\
\hline \multicolumn{2}{|l|}{ Disease severity } \\
\hline Mild (\%) & 28.7 \\
\hline Moderate (\%) & 42.6 \\
\hline Severe/very severe (\%) & 28.7 \\
\hline$\geq 1$ exacerbation in the previous year (\%) & 42.6 \\
\hline Inhaled long-acting bronchodilator use (\%) & 72.3 \\
\hline Inhaled corticosteroid use (\%) & 68.1 \\
\hline Systemic corticosteroid use (\%) & 8.5 \\
\hline
\end{tabular}

Age, body surface area, body mass index, and FEV ${ }_{1}$ are given as the mean with standard deviations. Smoking history, blood eosinophil levels and counts, FeNO, and total IgE levels are shown as the median with an interquartile range because of their skewed distributions. Other variables are given as the number of cases and percentages. The eosinophilic component was defined as blood eosinophil $\geq 5 \%$ and/or $\geq 300 / \mu$. High FeNO was defined as $>35$ ppb. Bronchial reversibility was defined as $\geq 12 \%$ and $\geq 200 \mathrm{ml}$ reversibility in post-bronchodilator FEV 1 . Positive levels for total IgE were defined as $>170 \mathrm{IU} / \mathrm{ml}$. Inhaled long-acting bronchodilator use referred to the use of long-acting $\beta_{2}$ agonists and/or long-acting muscarinic antagonists

$\mathrm{BMI}$, body mass index; FeNO, fractional exhaled nitric oxide; ppb, parts per billion; IgE, immunoglobulin $\mathrm{E}_{\text {; FEV }}$, forced expiratory volume in $1 \mathrm{~s}$

groups $(\mathrm{HR}=1.31$ (95\% CI 0.55-3.11)) (Fig. 3). As shown in Fig. 4 , there was a significant linear trend between $\mathrm{K}_{\mathrm{CO}}$ $\%$ pred and the incidence of exacerbation $(P=0.003$ for the trend). Compared with the highest tertile group, the multivariable-adjusted $\mathrm{HR}$ for ACO exacerbations was significantly higher in the lowest tertile group $(\mathrm{HR}=7.39$ (95\% CI 1.94-28.2)). Meanwhile, the association of $\mathrm{D}_{\mathrm{LCO}}$ $\%$ pred with exacerbations failed to reach statistical significance $(P=0.14$ for the trend). Broadly similar results were obtained in the analysis among patients without systemic corticosteroid use (Additional file 1: e-Figs. 1-3) and the analysis using ERS GLI reference equations (Additional file 1: e-Figs. 4-6).

\section{Discussion}

The present study revealed the prevalence of both low $\mathrm{D}_{\mathrm{LCO}}$ and low $\mathrm{K}_{\mathrm{CO}}$ in about one-third of the patients with ACO. There were inverse associations of $\mathrm{FEV}_{1}$ and the use of ICSs with low $\mathrm{D}_{\mathrm{LCO}}$, while low $\mathrm{K}_{\mathrm{CO}}$ was associated positively with the presence of emphysema and negatively with BMI. Our study also showed that impaired $\mathrm{K}_{\mathrm{CO}} \%$ pred was a significant risk factor for exacerbation of ACO. To the best of our knowledge, this is the first study to evaluate the distributions of $\mathrm{D}_{\mathrm{LCO}} \%$ pred and $\mathrm{K}_{\mathrm{CO}} \%$ pred, investigate risk factors, and estimate the amount of their impacts on exacerbations in ACO patients. 


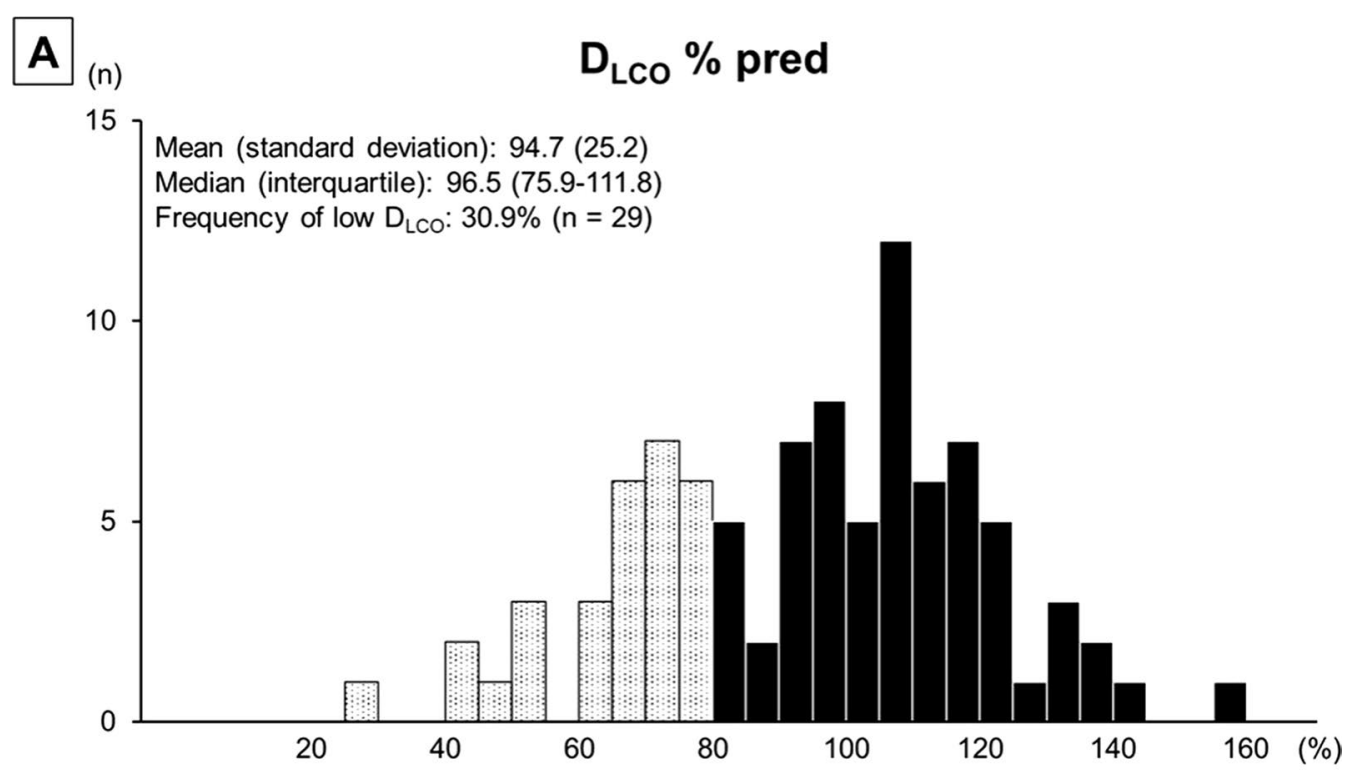

B

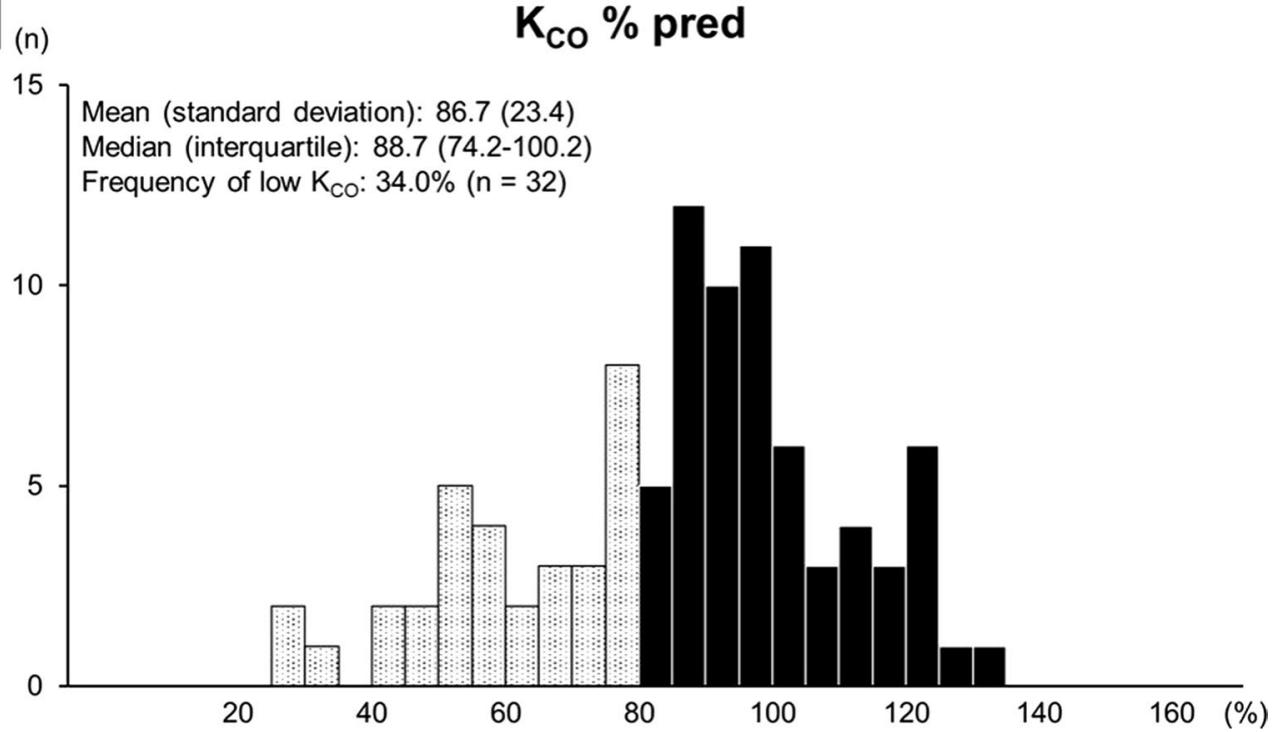

Fig. 1 Distribution of diffusing capacity $(\mathbf{A})$ and transfer coefficient $(\mathbf{B})$ of the lung per predicted among the total cohort. $D_{L C O} \%$ pred, diffusing capacity for carbon monoxide per predicted; $K_{\text {co }} \%$ pred, transfer coefficient for carbon monoxide per predicted

In the present research, low $\mathrm{K}_{\mathrm{CO}}$ was an independent risk factor for severe exacerbations of ACO, while low $\mathrm{D}_{\mathrm{LCO}}$ was not. As to COPD, the most robust predictors of future exacerbation had been considered to be a reduction in $\mathrm{FEV}_{1}$ and a history of exacerbations in the previous year [5, 14-17]. In addition, recent large-scale cohort studies demonstrated that impaired diffusing capacity was also strongly associated with increased rates of exacerbation among subjects with COPD $[6,18]$. As compared to $\mathrm{D}_{\mathrm{LCO}}, \mathrm{K}_{\mathrm{CO}}$ better reflects smoking-related injury of the lung in asthma as well as COPD patients [19]; in the current research, $\mathrm{K}_{\mathrm{CO}}$ is speculated to be a stronger risk factor than $\mathrm{D}_{\mathrm{LCO}}$ for exacerbations in ACO. Since diffusion capacity and gas transfer correlate with exercise capacity in COPD patients [20], deficits in $\mathrm{K}_{\mathrm{CO}}$ can lead to exercise inactivity, physical deconditioning, and disease advances. Taking into account the multivariable adjustment made in the current research methods, $\mathrm{K}_{\mathrm{CO}}$ might be a more appropriate biomarker than the previously established ones (e.g., $\mathrm{FEV}_{1}$ and exacerbation history) to detect the frequent-exacerbation phenotype of $\mathrm{ACO}$, although further investigation is needed. 
Table 2 Multivariable-adjusted odds ratios of potential risk factors for low $D_{L C O}$

\begin{tabular}{|c|c|c|c|c|}
\hline \multirow[t]{2}{*}{ Variables } & \multicolumn{2}{|c|}{ Number of events/cases (\%) } & \multirow{2}{*}{$\begin{array}{l}\text { Multivariable-adjusted OR } \\
(95 \% \mathrm{Cl})\end{array}$} & \multirow[t]{2}{*}{$P$ value } \\
\hline & Exposure group & Reference group & & \\
\hline Male gender & $21 / 77(27.3 \%)$ & $8 / 17(47.3 \%)$ & $0.90(0.18-4.40)$ & 0.89 \\
\hline Age (per 10-year increase) & N/A & N/A & $0.83(0.41-1.66)$ & 0.60 \\
\hline BMI (per 1 kg/m² increase) & $\mathrm{N} / \mathrm{A}$ & $\mathrm{N} / \mathrm{A}$ & $1.03(0.86-1.22)$ & 0.76 \\
\hline $\mathrm{FEV}_{1}($ per $1 \mathrm{~L}$ increase) & N/A & N/A & $0.29(0.10-0.76)$ & 0.02 \\
\hline Inhaled long-acting bronchodilator use & $22 / 68(32.4 \%)$ & $7 / 26(26.9 \%)$ & $8.42(0.93-108)$ & 0.07 \\
\hline ICS use & $17 / 64(26.6 \%)$ & $12 / 30(40.0 \%)$ & $0.07(0.01-0.59)$ & 0.02 \\
\hline \multicolumn{5}{|l|}{ COPD-like features } \\
\hline Smoking history $\geq 10$ pack-years & 28/87 (32.2\%) & $1 / 7(14.3 \%)$ & $3.32(0.34-80.7)$ & 0.36 \\
\hline Emphysema & 22/64 (34.4\%) & $7 / 30(23.3 \%)$ & $1.32(0.39-4.77)$ & 0.66 \\
\hline \multicolumn{5}{|l|}{ Asthmatic features } \\
\hline Eosinophilic component & 18/56 (32.1\%) & $11 / 38(28.9 \%)$ & $1.65(0.51-5.71)$ & 0.41 \\
\hline High FeNO & $11 / 44(25.0 \%)$ & $18 / 50(36.0 \%)$ & $0.51(0.15-1.61)$ & 0.26 \\
\hline $\begin{array}{l}\text { Positive levels for total lgE and/or lgE specific to } \\
\text { perennial inhalant antigens }\end{array}$ & $21 / 75$ (28.0\%) & $8 / 19(42.1 \%)$ & $0.51(0.12-2.06)$ & 0.34 \\
\hline Bronchial reversibility & 5/18 (27.8\%) & 24/76 (31.6\%) & $1.08(0.24-4.20)$ & 0.92 \\
\hline
\end{tabular}

Adjustment was made for age, gender, BMI, FEV , long-acting bronchodilator use, ICS use, a smoking history of > 10 pack-years, emphysema, high FeNO, bronchial reversibility, an eosinophilic component, and positive levels for total lgE and/or lgE specific to perennial inhalant antigens. The eosinophilic component was defined as blood eosinophil $\geq 5 \%$ and/or $\geq 300 / \mu$ l. High FeNO was defined as $\geq 35$ parts per billion. Bronchial reversibility was defined as $\geq 12 \%$ and $\geq 200 \mathrm{ml}$ reversibility in post-bronchodilator $\mathrm{FEV}_{1}$. Positive levels for total $\mathrm{lgE}$ were defined as $>170 \mathrm{IU} / \mathrm{ml}$

OR, odds ratio; $95 \% \mathrm{Cl}, 95 \%$ confidence interval; BMI, body mass index; FEV , forced expiratory volume in 1 s; ICS, inhaled corticosteroid; COPD, chronic obstructive pulmonary disease; N/A, not applicable

Table 3 Multivariable-adjusted odds ratios of potential risk factors for low $\mathrm{K}_{\mathrm{CO}}$

\begin{tabular}{|c|c|c|c|c|}
\hline \multirow[t]{2}{*}{ Variables } & \multicolumn{2}{|c|}{ Number of events/cases (\%) } & \multirow{2}{*}{$\begin{array}{l}\text { Multivariable-adjusted OR } \\
(95 \% \mathrm{Cl})\end{array}$} & \multirow[t]{2}{*}{$P$ value } \\
\hline & Exposure group & Reference group & & \\
\hline Male gender & 28/77 (36.4\%) & $4 / 17(23.5 \%)$ & $1.77(0.26-13.5)$ & 0.56 \\
\hline Age (per 10-year increase) & N/A & N/A & $1.12(0.52-2.41)$ & 0.77 \\
\hline BMI (per 1 kg/m² increase) & N/A & N/A & $0.73(0.57-0.90)$ & $<0.01$ \\
\hline $\mathrm{FEV}_{1}($ per $1 \mathrm{~L}$ increase) & N/A & $\mathrm{N} / \mathrm{A}$ & $1.67(0.62-4.72)$ & 0.32 \\
\hline Inhaled long-acting bronchodilator use & $24 / 68(35.3 \%)$ & $8 / 26(30.8 \%)$ & $2.22(0.25-23.1)$ & 0.48 \\
\hline ICS use & $21 / 64(32.8 \%)$ & $11 / 30(36.7 \%)$ & $0.74(0.08-6.52)$ & 0.79 \\
\hline \multicolumn{5}{|l|}{ COPD-like features } \\
\hline Smoking history $\geq 10$ pack-years & $30 / 87(34.5 \%)$ & $2 / 7(28.6 \%)$ & $1.84(0.20-21.9)$ & 0.60 \\
\hline Emphysema & 29/64 (45.3\%) & $3 / 30(10.0 \%)$ & $7.37(1.81-40.3)$ & $<0.01$ \\
\hline \multicolumn{5}{|l|}{ Asthmatic features } \\
\hline Eosinophilic component & $21 / 56(37.5 \%)$ & $11 / 38(28.9 \%)$ & $2.20(0.66-8.14)$ & 0.21 \\
\hline High FeNO & $12 / 44(27.3 \%)$ & $20 / 50(40.0 \%)$ & $0.36(0.09-1.23)$ & 0.11 \\
\hline $\begin{array}{l}\text { Positive levels for total lgE and/or lgE specific to } \\
\text { perennial inhalant antigens }\end{array}$ & 21/75 (28.0\%) & $11 / 19$ (57.9\%) & $0.42(0.09-1.70)$ & 0.23 \\
\hline Bronchial reversibility & $5 / 18(27.8 \%)$ & $27 / 76(35.5 \%)$ & $0.47(0.09-2.15)$ & 0.35 \\
\hline
\end{tabular}

Adjustment was made for age, gender, BMI, FEV , long-acting bronchodilator use, ICS use, a smoking history of $>10$ pack-years, emphysema, high FeNO, bronchial reversibility, an eosinophilic component, and positive levels for total IgE and/or lgE specific to perennial inhalant antigens. The eosinophilic component was defined as blood eosinophil $\geq 5 \%$ and/or $\geq 300 / \mu l$. High FeNO was defined as $\geq 35$ parts per billion. Bronchial reversibility was defined as $\geq 12 \%$ and $\geq 200 \mathrm{ml}$ reversibility in post-bronchodilator $\mathrm{FEV}_{1}$. Positive levels for total lgE were defined as $>170 \mathrm{IU} / \mathrm{ml}$

OR, odds ratio; $95 \% \mathrm{Cl}, 95 \%$ confidence interval; BMI, body mass index; FEV , forced expiratory volume in 1 s; ICS, inhaled corticosteroid; COPD, chronic obstructive pulmonary disease; N/A, not applicable 


\section{Diffusing capacity}

\section{Transfer coefficient}

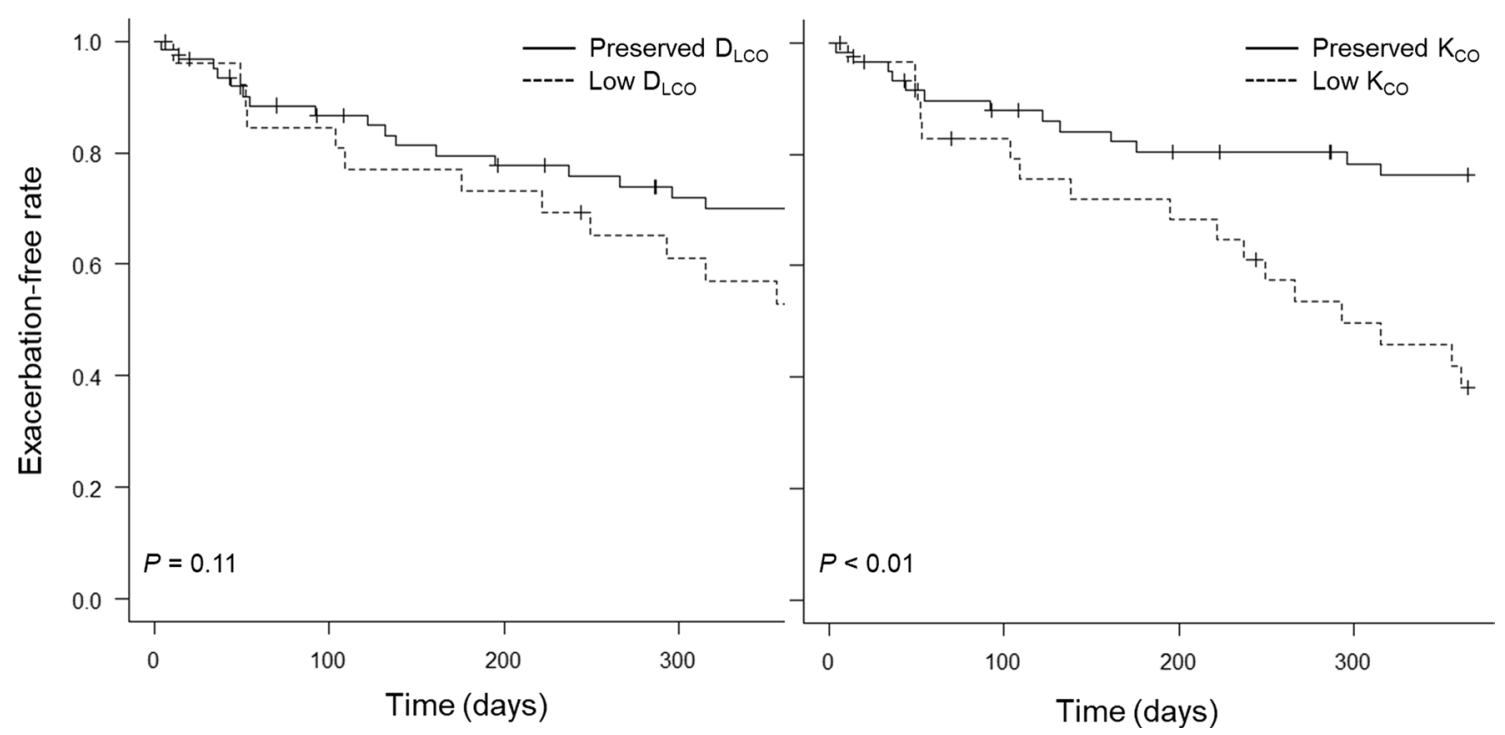

Fig. 2 The exacerbation-free rate in one year according to the levels of diffusion capacity or transfer coefficient of the lung. Low and preserved $D_{L c 0}$ were defined as $\mathrm{D}_{\mathrm{LCO}} \%$ pred $<80 \%$ and $\geq 80 \%$, respectively. In the same manner, low and preserved $\mathrm{K}_{\mathrm{CO}}$ indicated $\mathrm{K}_{\mathrm{CO}} \%$ pred $<80 \%$ and $\geq 80 \%$, respectively

\section{Diffusing capacity}

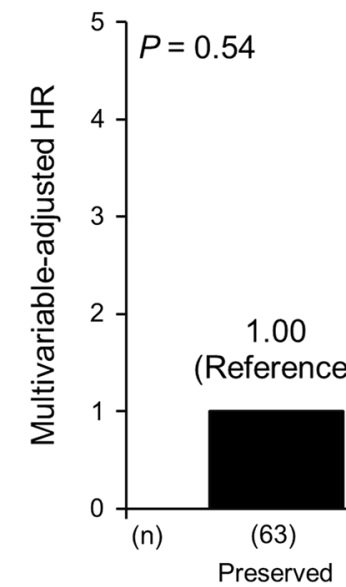

\section{Transfer coefficient}

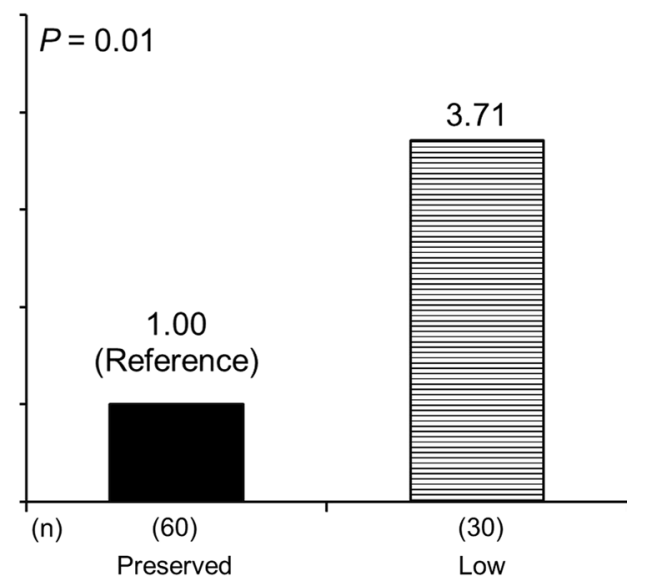

Fig. 3 The multivariable-adjusted hazard ratios for exacerbation by the levels of diffusion capacity or transfer coefficient of the lung. HR, hazard ratio. With regard to diffusing capacity, the preserved and low groups consisted of subjects with $\mathrm{D}_{\mathrm{LCO}} \%$ pred $\geq 80 \%$ and $<80 \%$, respectively. Similarly, the preserved- $\mathrm{K}_{\mathrm{CO}}$ and low- $\mathrm{K}_{\mathrm{CO}}$ group indicated subjects with $\mathrm{K}_{\mathrm{CO}} \%$ pred $<80 \%$ and $\geq 80 \%$, respectively

It has been well known that COPD is commonly accompanied by a reduction in diffusing capacity and transfer coefficient, while asthma is not [2]. In COPD, the pathophysiologic mechanisms underlying the deterioration of $\mathrm{D}_{\mathrm{LCO}}$ and $\mathrm{K}_{\mathrm{CO}}$ are due to alveolar destruction, namely emphysema, and alveolar microvascular damage preceding emphysematous changes [21]. On the other hand, regarding asthma, both $\mathrm{D}_{\mathrm{LCO}} \%$ pred and $\mathrm{K}_{\mathrm{CO}} \%$ pred are preserved or even increased to some extent because of the redistribution of pulmonary blood flow [22]. In our study, lung diffusion impairment was observed in only about one-third of the ACO cases; the pathophysiologic aspects of asthma may have 


\section{Diffusing capacity}

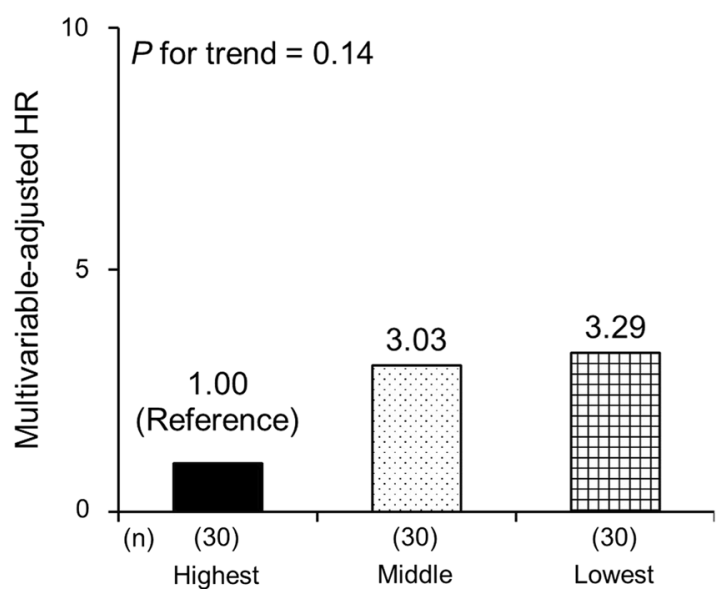

Transfer coefficient

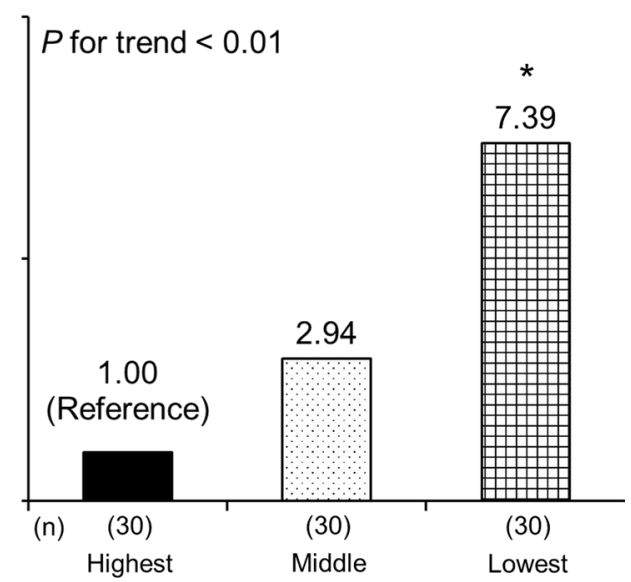

Fig. 4 The multivariable-adjusted hazard ratios for exacerbation according to the tertile of diffusion capacity or transfer coefficient of the lung. $H R$, hazard ratio. ${ }^{*} P<0.01$ versus the reference group. With regard to diffusing capacity, the cut-off values for $D_{1}$ co $\%$ pred are indicated as follows: highest, $\geq 108.73 \%$; middle, $82.1-108.72 \%$; and lowest, $\leq 82.0 \%$. Similarly, the cut-offs for $\mathrm{K}_{\text {co }} \%$ pred were $\geq 98.0 \%$ for the highest, $80.0-97.9 \%$ for the middle, and $\leq 79.9 \%$ for the lowest tertile group

compensated for the decline in gas diffusion and transfer due to COPD.

An increase in $\mathrm{FEV}_{1}$ was associated with a decrease in the prevalence of low $\mathrm{D}_{\mathrm{LCO}}$ in the current study. This is considered to be because $\mathrm{D}_{\mathrm{LCO}}$, not $\mathrm{K}_{\mathrm{CO}}$, is in proportion to lung volume, since $\mathrm{D}_{\mathrm{LCO}}$ is the product of $\mathrm{K}_{\mathrm{CO}}$ and alveolar volume at measurement. The relationship between ICS use and $\mathrm{D}_{\mathrm{LCO}}$ was compatible with previous reports; concomitant use of ICSs and LABDs has favourable effects on diffusing capacity, while LABD use alone does not $[23,24]$. The anti-inflammatory actions of ICSs might have prevented the progression of airflow limitation and lung hyperinflation, resulting in optimisation of the functionally available alveolar volume and the restoration of $\mathrm{D}_{\mathrm{LCO}}$ [23]. Another possible explanation is that ICS-prescribed patients were more asthmatic and less prone to develop deficits in $\mathrm{D}_{\mathrm{LCO}}$ than the others, although there was no significant difference in the frequency of highly asthmatic subjects between ICS users and nonusers in the current results.

In our research, emphysema was an independent risk factor for low $\mathrm{K}_{\mathrm{CO}}$. With regard to the effects of pulmonary emphysema on $\mathrm{K}_{\mathrm{CO}}$ and $\mathrm{D}_{\mathrm{LCO}}$ in the present study, similar results were observed among the cohort of patients with asthma or COPD [20], reinforcing the evidence that $\mathrm{K}_{\mathrm{CO}}$ is more sensitive than $\mathrm{D}_{\mathrm{LCO}}$ to detect the development of emphysema [25]. Considering the statistical significance after adjustment for alveolar volume substituted with $\mathrm{FEV}_{1}$, a high probability of $\mathrm{K}_{\mathrm{CO}}$ impairment in cases with emphysema might have been due to pulmonary microvascular remodelling as an early-stage change in COPD rather than emphysematous destruction per se [21]. It was also found that a higher BMI was inversely associated with the prevalence of not low $\mathrm{D}_{\mathrm{LCO}}$ but low $\mathrm{K}_{\mathrm{CO}}$, which was in accord with previous studies [26]. The association between $\mathrm{BMI}$ and $\mathrm{K}_{\mathrm{CO}}$ was likely to be attributed to an increase in pulmonary capillary blood volume among the obese [26, 27]. Meanwhile, in obesity, an increase in abdominal pressure and mechanical constraint placed on the chest wall by fat accumulation leads to low lung volumes and, consequently, attenuates the impact of elevated $\mathrm{K}_{\mathrm{CO}}$ on $\mathrm{D}_{\mathrm{LCO}}[26,28]$.

The strengths of our study were the highly accurate diagnosis of ACO using various objective measurements to assess the likelihood of asthma and COPD, the uniformity in measurements of $\mathrm{D}_{\mathrm{LCO}}$ and $\mathrm{K}_{\mathrm{CO}}$ by virtue of single-centre outcomes, the use of regression models adjusting for multiple confounders to evaluate the independent effects of $\mathrm{D}_{\mathrm{LCO}}$ and $\mathrm{K}_{\mathrm{CO}}$, and the prospective research design to minimise the potential of reverse causation.

However, some potential limitations should be noted. First, both $\mathrm{D}_{\mathrm{LCO}}$ and $\mathrm{K}_{\mathrm{CO}}$ values were based on a single measurement. This may cause misclassification of the levels of potential for gas exchange, which could have weakened the associations found in the present study, biasing the results toward a null hypothesis. Second, the present outcomes might lack external validity and generalisability due to the study design as single-centre analyses, although the characteristics of the study population were substantially comparable to those of other multicentre cohorts $[29,30]$. Third, systemic corticosteroid 
therapy might have affected the current results. However, among the study cohort, the proportion of subjects with systemic corticosteroid exposure was only $8.5 \%$. Furthermore, a sensitivity analysis excluding the patients with systemic corticosteroid use showed results consistent with those in the primary analysis. Thus, this limitation may not be critical.

Fourth, we did not have access to the data on air-trapping measurement due to the retrospective nature of the study. Fifth, we were unable to adjust the confounding effects of active smoking due to a lack of data concerning the present status of smoking or blood carboxyhaemoglobin concentration. Instead, through the present analysis, the number of pack-years of cigarette smoking was adjusted, along with other covariates. Sixth, the reference equations for $\mathrm{D}_{\mathrm{LCO}}$ and $\mathrm{K}_{\mathrm{CO}}$ applied in the main analyses might not have been applicable to the cohort subjects. However, a sensitivity analysis using the GLI reference equation provided outcomes similar to those in the primary analysis; this limitation would not have changed our conclusion. Seventh, we defined persistent airflow limitation as post-BD $\mathrm{FEV}_{1} / \mathrm{FVC}<70 \%$, not the lower limit of normal, based on findings from a large-scale general-population cohort study [31] and the official report of the Global Initiative for Chronic Obstructive Lung Disease [32].

Eighth, the possibility of overlooking early emphysema could not be denied, although ACO and COPD were assessed and diagnosed based on smoking history and the existence of persistent airflow limitation, as well as CT images; early emphysema without COPD was therefore ruled out in the study population [33]. Ninth, we did not have access to a tool for radiological assessment of the severity of pulmonary emphysema and lung volume. Instead of the severity of emphysema and lung volume, the value of $\mathrm{FEV}_{1}$ was adjusted in the analyses. Lastly, there was a possibility of confounding effects of inhaler medications on the present results. However, it has been reported that an LABD was unable to contribute to significant improvements in either $\mathrm{D}_{\mathrm{LCO}}$ or $\mathrm{K}_{\mathrm{CO}}$ [24]. Combined use of an ICS and LABD could have been favourable for both the diffusion capacity and exacerbation rate [23] and might have affected the associations between $\mathrm{D}_{\mathrm{LCO}}$ or $\mathrm{K}_{\mathrm{CO}}$ and exacerbation events. However, the present outcomes were demonstrated after adjustment for inhaler use, suggesting that this potential limitation may not have altered our conclusions.

\section{Conclusions}

About one-third of the cases of ACO presented with low $\mathrm{D}_{\mathrm{LCO}}$, which was associated with decreased $\mathrm{FEV}_{1}$. The prevalence of low $\mathrm{K}_{\mathrm{CO}}$ was comparable to that of impaired $\mathrm{D}_{\mathrm{LCO}}$ and was higher in the subjects with emphysema. Additionally, low $\mathrm{K}_{\mathrm{CO}}$ was an independent risk factor for ACO exacerbations, and there was a linear trend in the risk of exacerbation across the level of $\mathrm{K}_{\mathrm{CO}} \%$ pred. Since $\mathrm{K}_{\mathrm{CO}}$ is superior to $\mathrm{DL}_{\mathrm{CO}}$ in reflecting initial development of microvascular or parenchymal damage of the lung in $\mathrm{ACO}, \mathrm{K}_{\mathrm{CO}}$ may be more useful than $\mathrm{D}_{\mathrm{LCO}}$ for predicting the future risk of exacerbations. In clinical practice, $\mathrm{ACO}$ patients with low $\mathrm{K}_{\mathrm{CO}}$ should be carefully monitored due to their high potential for exacerbations. Further research is warranted to clarify whether $\mathrm{K}_{\mathrm{CO}}$ is a biomarker for mortality in subjects with ACO.

\section{Abbreviations}

COPD: Chronic obstructive pulmonary disease; ACO: Asthma-COPD overlap; $D_{L c o}$ : Diffusing capacity of the lung for carbon monoxide; $K_{C O}$ :Transfer coefficient of the lung for carbon monoxide; BD: Bronchodilator; FEV $/$ /FVC: Forced expiratory volume in $1 \mathrm{~s}$ to forced vital capacity; FeNO: Fractional exhaled nitric oxide; ppb: Parts per billion; ATS/ERS: American Thoracic Society/European Respiratory Society; IgE: Immunoglobulin E; \% pred: Percent predicted; GLI: Global Lung Function Initiative; CT: Computed tomography; LABD: Long-acting bronchodilator; ICS: Inhaled corticosteroid; BMI: Body mass index; GOLD: Global Initiative for Chronic Obstructive Lung Disease; HR: Hazard ratio; OR: Odds ratio; 95\% Cls: 95\% Confidence intervals.

\section{Supplementary Information}

The online version contains supplementary material available at https://doi. org/10.1186/s12890-021-01815-w.

Additional file 1. Supplementary materials (e-Figs. 1-6)

\section{Acknowledgements}

We thank Chief Radiologist Yuko Tateshi for interpretation of the chest CT images.

\section{Authors' contributions}

H.O. contributed to the study concept, data collection, data interpretation, statistical analysis, and drafting of the manuscript. A.M., K.K., A.E-O., Y.J., A.I., K.T., H.N., and H.A. contributed to data collection, data interpretation, and revision of the manuscript. M.Y. contributed to the study concept, data collection, data interpretation, and revision of the manuscript. All authors read and approved the final manuscript.

\section{Funding}

This research did not receive any specific grant from funding agencies in the public, commercial, or not-for-profit sectors.

\section{Availability of data and materials}

The datasets used and/or analysed during the current study are available from the corresponding author on reasonable request.

\section{Declarations}

Ethics considerations and consent to participate

The study was approved by the National Hospital Organization Fukuoka National Hospital Institutional Review Board for Clinical Research (\#F3-3). Given the retrospective nature of the study, a written informed consent was not requested by the ethics committee.

Consent for publication

Not applicable. 


\section{Competing interests}

The authors declare that they have no competing interests.

Received: 15 June 2021 Accepted: 23 December 2021

Published online: 12 January 2022

\section{References}

1. Gibson PG, Simpson JL. The overlap syndrome of asthma and COPD: what are its features and how important is it? Thorax. 2009;64:728-35.

2. A Joint Project of GINA and GOLD. Diagnosis and initial treatment of asthma, COPD, and asthma-COPD overlap. https://ginasthma.org/ wp-content/uploads/2019/11/GINA-GOLD-2017-overlap-pocket-guidewms-2017-ACO.pdf. Date last accessed: June 1, 2021.

3. Alshabanat A, Zafari Z, Albanyan O, Dairi M, Fitzgerald JM. Asthma and COPD overlap syndrome (ACOS): a systematic review and meta analysis. PLoS ONE. 2015;10:e0136065.

4. Hughes JMB, Pride NB. Examination of the carbon monoxide diffusing capacity (DLCO) in relation to its KCO and VA components. Am J Respir Crit Care Med. 2012;186:132-9.

5. Guerra B, Gaveikaite V, Bianchi C, Puhan MA. Prediction models for exacerbations in patients with COPD. Eur Respir Rev. 2017;26:160061.

6. Balasubramanian A, Macintyre NR, Henderson RJ, Jensen RL, Kinney G, Stringer WW, et al. Diffusing capacity of carbon monoxide in assessment of COPD. Chest. 2019:156:1111-9.

7. Miller MR, Hankinson J, Brusasco V, Burgos F, Casaburi R, Coates A, et al. Standardisation of spirometry. Eur Respir J. 2005;26:319-38.

8. Burrows B, Kasik JE, Niden AH, Barclay WR. Clinical usefulness of the single-breath pulmonary diffusing capacity test. Am Rev Respir Dis. 1961:84:789-806.

9. Stanojevic S, Graham BL, Cooper BG, Thompson BR, Carter KW, Francis RW, et al. Official ERS technical standards: global Lung Function Initiative reference values for the carbon monoxide transfer factor for Caucasians. Eur Respir J. 2017;50:1700010.

10. Clinical Pulmonary Functions Committee of the Japanese Respiratory Society. Guidelines of respiratory function tests: spirometry, flow-volume curve, diffusion capacity of the lung [in Japanese]. Tokyo: The Japanese Respiratory Society; 2004

11. Vogelmeier CF, Criner GJ, Martinez FJ, Anzueto A, Barnes PJ, Bourbeau J, et al. Global strategy for the diagnosis, management, and prevention of chronic obstructive lung disease 2017 report: GOLD executive summary. Am J Respir Crit Care Med. 2017;195:557-82.

12. Kubota M, Kobayashi H, Quanjer PH, Omori H, Tatsumi K, Kanazawa M Reference values for spirometry, including vital capacity, in Japanese adults calculated with the LMS method and compared with previous values. Respir Investig. 2014;52:242-50.

13. Reddel HK, Taylor DR, Bateman ED, Boulet L-P, Boushey HA, Busse WW, et al. An official American Thoracic Society/European Respiratory Society statement: asthma control and exacerbations: standardizing endpoints for clinical asthma trials and clinical practice. Am J Respir Crit Care Med 2009;180:59-99.

14. Müllerova H, Maselli DJ, Locantore N, Vestbo J, Hurst JR, Wedzicha JA, et al. Hospitalized exacerbations of COPD risk factors and outcomes in the ECLIPSE cohort. Chest. 2015;147:999-1007.

15. Soriano JB, Lamprecht B, Ramírez AS, Martinez-Camblor P, Kaiser B, Alfageme I, et al. Mortality prediction in chronic obstructive pulmonary disease comparing the GOLD 2007 and 2011 staging systems: a pooled analysis of individual patient data. Lancet Respir Med. 2015;3:443-50.

16. Hurst JR, Vestbo J, Anzueto A, Locantore N, Müllerova H, Tal-Singer R, et al. Susceptibility to exacerbation in chronic obstructive pulmonary disease. N Engl J Med. 2010;363:1128-38.

17. Le Rouzic O, Roche N, Cortot AB, Tillie-Leblond I, Masure F, Perez T, et al. Defining the "frequent exacerbator" phenotype in COPD: a hypothesisfree approach. Chest. 2018;153:1106-15.

18. Lee HY, Kim JW, Lee SH, Yoon HK, Shim JJ, Park J-W, et al. Lower diffusing capacity with chronic bronchitis predicts higher risk of acute exacerbation in chronic obstructive lung disease. J Thorac Dis. 2016;8:1274-82.

19. Shimizu K, Konno S, Makita H, Kimura H, Kimura H, Suzuki M, et al. Transfer coefficients better reflect emphysematous changes than carbon monoxide diffusing capacity in obstructive lung diseases. J Appl Physiol. 2018;125:183-9.

20. Behnia M, Wheatley C, Avolio A, Johnson B. Influence of resting lung diffusion on exercise capacity in patients with COPD. BMC Pulm Med. 2017;17:117.

21. Santos S, Peinado VI, Ramırez J, Melgosa T, Roca J, Rodriguez-Roisin R, et al. Characterization of pulmonary vascular remodelling in smokers and patients with mild COPD. Eur Respir J. 2002;19:632-8.

22. Collard P, Njinou B, Nejadnik B, Keyeux A, Frans A. Single breath diffusing capacity for carbon monoxide in stable asthma. Chest. 1994;105:1426-9.

23. Pelaia C, Procopio G, Deodato MR, Florio O, Maglio A, Sciacqua A, et al. Real-life clinical and functional effects of fluticasone furoate/umeclidinium/vilanterol-combined triple therapy in patients with chronic obstructive pulmonary disease. Respiration. 2021;100:127-34.

24. Santus P, Radovanovic D, Mascetti S, Pauletti A, Valenti V, Mantero M, et al. Effects of bronchodilation on biomarkers of peripheral airway inflammation in COPD. Pharmacol Res. 2018;133:160-9.

25. Mochizuki T, Nakajima H, Kokubu F, Kushihashi T, Adachi M. Evaluation of emphysema in patients with reversible airway obstruction using highresolution CT. Chest. 1997;112:1522-6.

26. Enache I, Oswald-Mammosser M, Scarfone S, Simon C, Schlienger J-L, Geny B, et al. Impact of altered alveolar volume on the diffusing capacity of the lung for carbon monoxide in obesity. Respiration. 2011;81:217-22.

27. Oppenheimer BW, Berger KI, Rennert DA, Pierson RN, Norman RG, Rapoport DM, et al. Effect of circulatory congestion on the components of pulmonary diffusing capacity in morbid obesity. Obesity. 2006;14:1172-80.

28. Zavorsky GS, Kim DJ, McGregor ER, Starling JM, Gavard JA. Pulmonary diffusing capacity for nitric oxide during exercise in morbid obesity. Obesity. 2008;16:2431-8.

29. Suzuki M, Makita H, Konno S, Shimizu K, Kimura H, Kimura H, et al. Asthma-like features and clinical course of chronic obstructive pulmonary disease: an analysis from the Hokkaido COPD Cohort Study. Am J Respir Crit Care Med. 2016;194:1358-65.

30. Tamada T, Sugiura H, Takahashi T, Matsunaga K, Kimura K, Katsumata U, et al. Biomarker-based detection of asthma-COPD overlap syndrome in COPD populations. Int J COPD. 2015;10:2169-76.

31. Bhatt SP, Balte PP, Schwartz JE, Cassano PA, Couper D, Jacobs DR, et al.

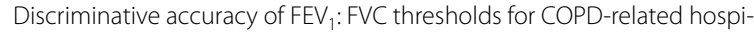
talization and mortality. JAMA. 2019;321:2438-47.

32. Global Initiative for Chronic Obstructive Pulmonary Disease. 2020 GOLD Reports. 2020 Global strategy for prevention, diagnosis and management of COPD. Available at https://goldcopd.org/gold-reports/. Accessed 1 Sept 2021.

33. Global Initiative for Asthma. Global strategy for asthma management and prevention (updated 2021). https://ginasthma.org/gina-reports/. Accessed 1 Sept 2021.

\section{Publisher's Note}

Springer Nature remains neutral with regard to jurisdictional claims in published maps and institutional affiliations.

Ready to submit your research? Choose BMC and benefit from

- fast, convenient online submission

- thorough peer review by experienced researchers in your field

- rapid publication on acceptance

- support for research data, including large and complex data types

- gold Open Access which fosters wider collaboration and increased citations

- maximum visibility for your research: over 100M website views per year

At BMC, research is always in progress.

Learn more biomedcentral.com/submissions 